AC 2007-1570: PRODUCT INNOVATION ENGINEERING PROGRAM: TRAINING STUDENTS IN ENTREPRENEURIAL THINKING

Martin Grimheden, Royal Institute of Technology (KTH) 


\title{
Product Innovation Engineering Program: Training Students in Entrepreneurial Thinking
}

\begin{abstract}
When measuring innovation in Europe, Sweden is in the top end concerning resources put into research; almost in the top concerning education, but behind concerning innovation. $\mathrm{KTH}$, the largest technical university in Sweden, has set out on a path to create a systematic change affecting engineering education toward innovation engineering and entrepreneurial thinking in general. This article presents the overall idea together with examples of educational activities with a particular focus on a new course aimed at finding, selecting and developing innovative student ideas and motivating these students to start developing their ideas into new businesses.
\end{abstract}

\section{Introduction}

In 2005, representatives of KTH, the Royal Institute of Technology in Stockholm, Sweden, together with a number of industrial partners took the initiative to develop a large national R\&Dprogram with the purpose of strengthening Swedish ability in innovative product- and business development. A major aspect of the program is to create a systematic change in higher engineering education in product development, to push toward a focus on innovative product development, toward entrepreneurship and better utilization of student ideas. The intention was not to create new educational programs in innovation engineering, but rather to create a change in existing programs and curriculum. Examples are introduction of new courses in innovation engineering, integration between project courses, research projects, entrepreneurs and companies to better utilize student ideas and projects.

The aim of this article is to present the overall goals of the program, experiences from the establishment together with experiences and results from the introduction of a new large course aimed at bringing student ideas to the market.

\section{Industrial and Educational context}

The industrial history in Sweden can be characterized by a number of manufacturing companies that has grown to multinational corporations based mainly on technical innovations, with the examples of Volvo, SKF, Ericsson and Scania. The position is though challenged; several of the major companies have been acquired by international actors and the global competition forces decisions conveying that both activities and competencies disappear from Sweden. In a situation where work and related competence within production technology is transferred a worrisome development would be that also activities related to development are transferred to countries where the production now takes place ${ }^{1}$.

The potential to keep existing, and develop new, possibilities for businesses can be related to the ability to develop innovative products, organizations and businesses, within areas where a high level of competence exists in Sweden. From an educational point of view, Sweden is 
characterized by well-trained engineers, by a high level of competence with the population at large and with a democratic, non-hierarchic tradition.

When measuring innovation in Europe ${ }^{2}$, Sweden is in the top European end concerning resources in research, almost in the top concerning education but behind on innovation. The focus is therefore quite clear; resources are put into place regarding research - industrial as well as academic. Higher education is among the best in Europe. But, the knowledge, skills and experience in research and education are not utilized into innovative product development.

Regarding educational context, the focus of this article and the educational efforts presented, is the area of product development, with a special focus on knowledge intensive products. This also relates to the industrial situation in Sweden; well-trained engineers, one of the best higher educations in Europe but with expensive manufacturing and a long trend of outsourcing.

\section{Product Innovation Engineering Program, PIEp}

The PIEp program encompasses the field from theory to practice, from research in innovation to directed activities aimed at strengthening Swedish innovative product development. PIEp is intended to run for ten years and yearly have a turn-around of approximately 5M€. PIEp is funded mainly by VINNOVA (the Swedish Governmental Agency for Innovation Systems) together with a number of other governmental financiers, companies, universities and private sponsors.

PIEp is based on activities in five fields: research in innovation (Innovation Knowledge), research and development in management for innovation (Innovation Management), activities for exchange of experience in innovation (Innovation Experience), activities for creating new businesses based on innovation (Innovation Business) and the creation of a systematic change of education in innovation (PIEp Education). The fundamental idea of PIEp is to keep these five fields together to create a synergistic exchange of knowledge, skills and experience between the fields.

The intention is not to describe PIEp in detail in this article, but it is of importance for the educational activities to understand the relation with the other fields. Innovation Knowledge constitutes the kick-start of the entire program; a massive research effort aimed at creating a base for the rest of the program. Innovation Management involves mainly action research aimed at performing change and effect upon participating companies, and to utilize research performed in Innovation Knowledge. Innovation Experience is built on a forum where knowledge and skills in innovation are utilized for participating partners; where innovators meet and where companies find a creative ground for innovative sessions with creative people. Innovation Experience also involves rotational programs between industry and academy and international collaborative programs. Innovation Business is built on activities aimed at utilizing research results, student projects, ideas etc. into products and businesses. Further, Innovation Business feeds back into Innovation Knowledge where new knowledge is gathered based on experiences and results from all other fields. 
Finally, PIEp Education is the fifth field that utilizes and feeds knowledge and skills to and from all other fields. Innovation Business, for example, utilizes student ideas and creates products and businesses from student projects. PIEp Education is nourished from the activities in Innovation Experience, Innovation Knowledge and Innovation Experience provides information for courses in innovation etc.

Activities in PIEp Education involves new courses in innovation, a network for doctoral students, exchange programs for students, rotational programs for faculty and better utilization of all existing mechanisms for bringing an idea to the market. Figure 1 shows an illustration of the 'learning cycle' of PIEp together with some keywords and key activities of the respective activity fields.

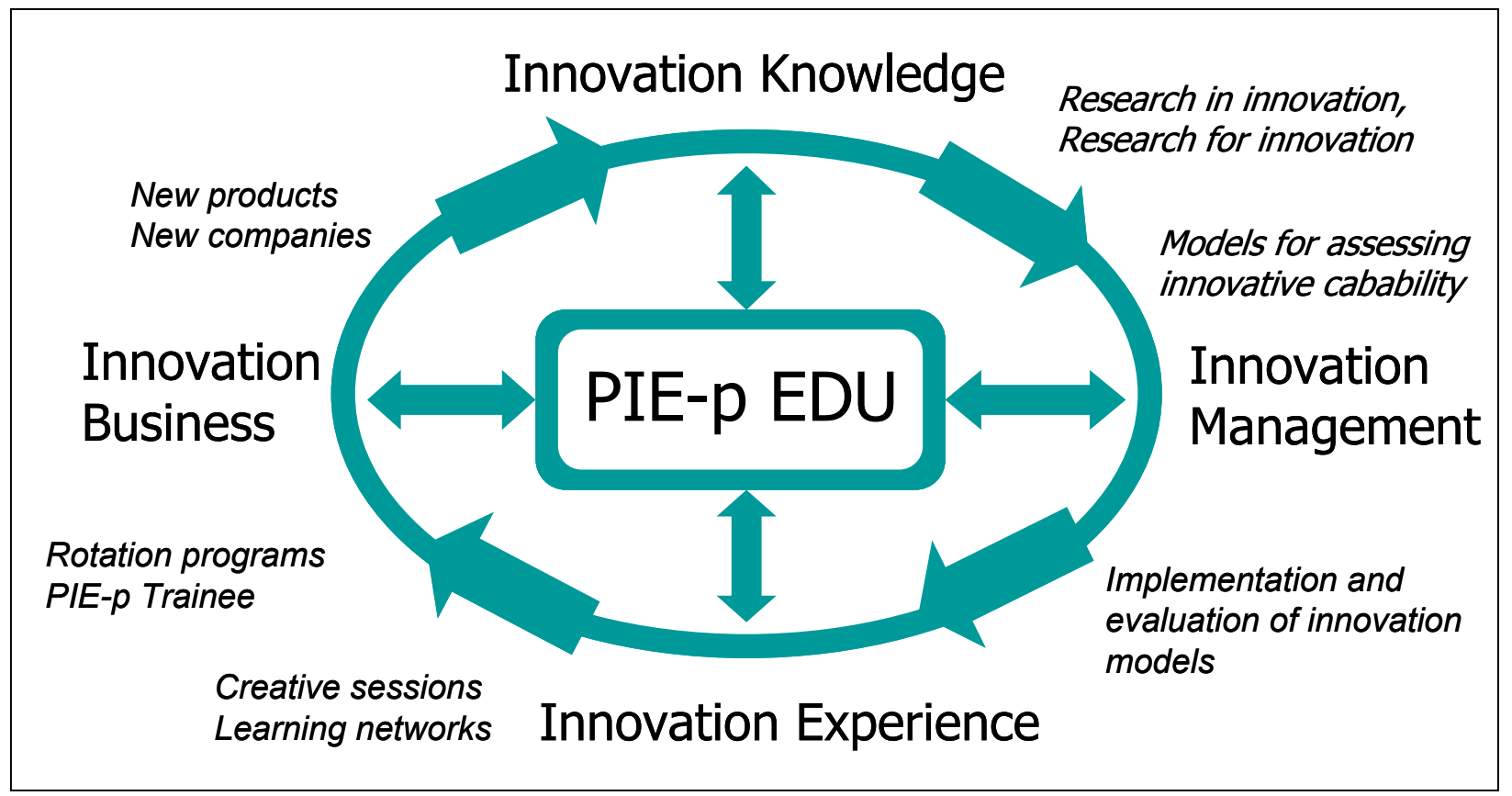

Figure 1. PIEp is illustrated with a 'learning cycle' to show how the five fields are related, with PIEp education as the central node - nourished from the outer five fields and providing ideas, material, students etc. to the other fields.

\section{PIEp Education}

The basic idea of PIEp Education is to view students as 'agents of change', both in universities and in companies. Newly graduated students working in companies can be bringing a fresh mindset and the possibility to inject unconventional ideas. Students, and newly graduates, have an advantage of not carrying a load of implicit knowledge and preconceived notions about how things are usually done. A program for 'students as agents of change' attracts students in the final years of their education and organizes mentorship networks, a lecture series and basically the transfer of knowledge and experience between these students and all other activities of the PIEp program. The 'agent'-program can also be seen as a network of interested students, where the network provides and establishes the roles and interests of these students, and creates a feeling of participation, membership and responsibility for the issues ${ }^{3,4}$. 
In a recent comparison between medical universities in Sweden and USA, a number of students were asked why they studied medicine. Of the students at the medical school in Stanford University, around $60 \%$ responded that they wanted to start their own company and be entrepreneurial within the area of medicine. Of the Swedish students, only $2 \%$ expressed these intentions.

The role of PIEp Education is to create awareness in Swedish engineering educational programs about product innovation and entrepreneurship. In most engineering programs students take courses in business administration and sometimes also entrepreneurship, but in small numbers and not correlated to the other engineering courses. The purpose of the PIEp program is therefore both to integrate new courses and educational programs in product innovation engineering, but perhaps more important to find mechanisms to entice students to constantly be on the lookout for new ideas, and to be prepared to take these ideas one step (or many) further than keeping the idea as 'only an idea'.

\section{A first course in innovative product- and business development}

The description of this course is provided here as a more explicit example of activities within PIEp Education. The basic idea of the course is to provide students with an attractive alternative to the traditional way of applying for a job immediately after graduation - to provide students with guidance toward entrepreneurship.

Students are recruited during their final year of studies, before the process of searching for a job has commenced. Typically, the students aimed for are either finishing their final courses, searching for a thesis project or currently undertaking a thesis project. The students are recruited from areas related to product development. The students are asked to present an idea for a product or a business. This idea is put in front of a jury consisting of representatives from the university, from industrial companies, from business coaches and seed capital representatives. Students are then accepted on basis of the potential of their respective ideas, and the course is based on the process of taking the ideas into products and onto the market.

The ideas are each judged according to the knowledge base of the student as well as the faculty. The students are required to put forward an idea that correlates to his or her specialization, and the idea is required to be built on knowledge and skill within this field. The field is also required to correlate with the fields of the faculty, meaning that the faculty must be able to provide guidance within this field. Typically, the ideas are expected to have sprung from student projects related to capstone courses, master thesis projects or student projects in general.

Similar courses and programs exist at other universities, but some particularities can be noted here. The course is currently focused on students within the two specializations (M.Sc. programs) of Mechatronics and Integrated product development, specializations which are open to students mainly from the programs (B.Sc.) of either Mechanical Engineering, Industrial Engineering and Management or Vehicle Engineering. The course is offered to these students as a complement to previously taken capstone courses. The course is also given by basically the same faculty, within the same context both related to the subject and the environment. Therefore, 
when faced with the option of taking this new course, the choice to take the course can be easier to make than choosing not to take the course, which would imply leaving the university and start searching for a job. Naturally, most students chooses the path of graduation and search for a job, but still the threshold of choosing an entrepreneurial path after graduation has suddenly been reduced to something which is mainly a question of having a good enough idea and initially leaving everything else in the hands of the course coordinators.

The course, Innovative Product- and Business Development, runs over a period of one year with a student engagement of 50\%. Students are encouraged to take the course either in parallel with a master thesis project, with other courses or with a regular job. The students also have the option, however discouraged from this, to study full time and finish within six months.

\section{The first students}

In August 2006, nine students with the total number of six ideas were accepted for the course. Three students brought individual ideas and three teams of two students each brought one idea per team. Eight of the nine students opted for half-time studies and one for full-time studies. Four students where in the middle of their master thesis project, one student had already finished his project and four students where in a stage of searching for thesis projects. The students' educational backgrounds where a combination of having either taken a B.Sc. program in Mechanical Engineering or in Vehicle Engineering and where either following a M.Sc. program in Integrated Product Development or in Mechatronics. Eight of the nine students were male.

\section{The first ideas}

Due to confidentiality issues none of the details can be described in detail, but it might be of importance to trace the idea back to its origin. Of the six ideas, two can be traced back to spinoffs from capstone projects performed during the fourth year of studies. One can be traced back to spin-offs from master thesis projects and three relates to ideas gained either from activities in students' spare time or are related to their personal interest.

To better understand the scope of the ideas and projects, three of the ideas will be described further.

\section{Idea A}

The idea was presented by one student, with B.Sc. in ME and a M.Sc. in Mechatronics. The student was at time of application searching for master thesis project, finishing unfinished courses and working part-time outside the university.

The idea relates to the students' educational specialization, and is a rather complex product combining Mechatronics, wireless communication and distributed embedded systems. The market for the product is mainly within sports, physical science and outdoor activities.

In terms of possible businesses, the final product is expected to be able to sell for an amount in the area of $100 €$, with the total potential in the area of tens of thousands units. 


\section{Idea B}

This idea was presented by two students, one with a B.Sc. in Vehicle Engineering and a M.Sc. in Integrated Product Development, and one with a B.Sc. in Mechanical Engineering and a M.Sc. in Integrated Product Development. Both students were performing their master thesis project at the time of application and had begun to search the job market for possible employments.

Their idea had emerged as a spin-off during a project within a capstone course the two students undertook together. They were performing a project for a corporate sponsor, and during a brainstorming session the students came up with a new application for a technology involved in the capstone project. The idea is basically not related to the students' specializations or not based on particularly advanced technology, but the applications required good knowledge about production technology and the manufacturing industry. The market for the new product is huge, with possible customers in basically the entire manufacturing industry. A typical application is expected to be sold in the area of $1000 €$, with a total potential in the area of millions of units.

\section{Idea C}

This idea was also presented by two students, each with a B.Sc. in Vehicle Engineering and a M.Sc. in Mechatronics. The students were performing their master thesis project at the time of application, with a local company.

Their idea evolved incrementally during their thesis project. This project was focused on building applications for demonstration of a particular technology related to the educational background of the students, which relates to distributed embedded systems and advanced motion control. The application was chosen together with the company, but the company did not express any interest in the application besides demonstrating their own product, and therefore the students could use the innovation as their own. The company simply did not consider the innovation to be in the line of their interest. An estimate of the final product is guessed to be sold for something in the area of $100 €$, with a total potential in the area of tens of thousands of units.

\section{Bringing the ideas to the market}

The students all brought their ideas, and they were accepted based on expected potential. The course were then mainly about having these people invest one year into an attempt at taking these ideas through a process ending up as a commercial success. This is also where the connection to PIEp became necessary.

The course is mainly divided into two large phases, each consisting of one semester. The first semester is dedicated to idea development, getting to know the State-of-the-art within the area; both related to product, technology and market. The aim is to push toward applying for a patent at the end of the first semester. The second phase, or semester, is dedicated to business development; gaining funding, creating business models, finding collaborative partners etc. Figure 2 shows a timeline of the course together with some keywords of activities performed in the course. Phase 1 relates to the first semester and Phase 2 to the second. The keywords also 
show collaborative actors such as business angels, and approximately when interaction is performed between these and the students.

The course is further based on the following mechanisms/fundamentals:

\section{Coaching of students}

Each student/student team is assigned three coaches. All coaches signs confidentiality agreements and are fully briefed on the ideas and projects. The technical coach is assigned early on in the course and is usually a senior faculty member interested in the particular area. This person provides technical guidance, helps in prototype design and provides access to the university's resources.

The innovative coach is also assigned early on in the course and is typically a person active in the industry with an entrepreneurial background. Typically this person have one or several own patents, have started a company and been around for both successes and failures.

The business coach is assigned in the second phase, or semester. This is a professional business coach hired by the university for the purpose of commercializing academic projects and ideas.

\section{Phase 1}

Focus: Innovation Technology

Activities: Idea selection Patent searches Prototype design

Brainstorming Idea development Business models

Deliverables: State-of-the-art review Patent

\section{Phase 2}
Focus:
Market
Business

Theme: From business establishment and development to entrepreneurship

Actors: Business coaches Incubators Business angels Seed capital
Deliverables:
Business plan
Business

Figure 2. The course structure is based on two phases. Each phase corresponds to one semester. 


\section{Creative sessions}

The students meet regularly to brainstorm and discuss their respective ideas. This is also pressed as one of the advantages of taking the course; even if the students are bringing their own ideas the students are working as a team and can benefit from their respective experiences.

A team of "innovation friends" constitutes an advisory team for the students. These "friends" are gathered among the faculty, industrial representatives and basically all sorts of creative people interested in innovative product development. This team provides extra nourishment for the brainstorming sessions.

\section{Utilizing the Swedish innovation system}

The Swedish innovation system consists of a complex system of actors, funded and coordinated either by the government, by governmental agencies, by regional agencies, by universities, by special interest groups etc. A list of approximately 30 actors covers most agencies, the important lecture series, relevant exhibitions etc. This list is divided among the students, each with the responsibility to both make sure that information from the actor is utilized and that somebody from the course participates in offered activities. The basic idea is that a course representative should be active in all activities in the region relevant to product innovation engineering to feed back relevant information to the course.

\section{Weekly team meetings}

The purpose of the weekly team meetings is to provide a forum for formalized exchange of information and to further establish the group of students as a team. Each student reports from his/her watch-area as well as the progress of the development of the ideas.

Typically, the students report on their progress and the team provides feedback and comments. A course organizer participates together with one or two faculty members who provide spontaneous feedback and creative suggestions.

The weekly meetings are also based on openness between each participant. All course participants have signed confidentiality agreements between each other, and the faculty members participating in these meetings have to agree on the confidentiality issues as well.

\section{Content providers}

This is the main interface with the rest of the PIEp program. In contrast to the weekly meetings these content providers usually does not sign confidentiality agreements and the discussions are more vague and general; the purpose is also to provide the team with this general knowledge. Typically, regular mini-courses are given by hired external professionals and PIEp partners. These mini-courses involve intellectual property rights, patents, business administration, idea development, innovation theory etc. 
This aspect of the course also involves student participation in external activities provided by other actors of the Swedish innovation system. Examples are participation in innovation competitions, existing lecture series and contacts with business coaches.

\section{The logbook}

Fundamental for most creative work is the idea log, scrap book or design log. Each student documents his/her own process, reflections and learning experience. This logbook is used and discussed in the project meetings to illustrate the process since last meeting.

\section{Synergistic integration}

In perspective of the PIEp program, the course described is dependant on receiving knowledge and experience from the other fields and using all possible mechanisms to succeed in bringing the ideas to the market. Through PIEp, access to mentors and coaches is facilitated as well as funding for external experts. PIEp receives a test-bed for better utilization of student ideas as well as a role model for how entrepreneurial thinking can be integrated into higher engineering education.

The main goal is however reached in due time when the idea of utilizing the student ideas has reached all levels of the university. It is not sufficient to recruit students at the end of their education, but instead should an awareness of this possibility be imminent with the students already from the first year of studies. The students should actively search for ideas and business possibilities during their education and select the best in their application.

\section{Concluding remarks}

The course presented and discussed in this chapter shows that it is possible to pull innovative students with innovative ideas from the final years of their education, and to use these students and ideas to promote a general increase in innovational and entrepreneurial thinking in the entire educational system. Patents are being filed, companies are getting started and financiers are offering seed capital. Now it is more a matter of creating enough buzz, talk and information from these experiences and to use this into the earlier years of the current educational programs as well as expanding to other programs, schools and universities. It is of high importance that students already from the first years (or days!) of university studies are aware of the possibility to take an entrepreneurial path, to be innovative and to constantly be aware for business opportunities and ideas.

\section{References}

1. The Swedish National Innovation System 1970-2003 - a quantitative international benchmarking analysis, VINNOVA analysis VA 2004:01.

2. T. C. McAloone, M. M. Andreasen, P. Boelskifte, A Scandinavian Model of Innovative product Development, Proceedings of the 2007 conference: The Future of Product Development, CIRP-2007, Berling, Germany. 
3. B. Clark, "Creating Entrepreneurial Universities: Organizational Pathways of Transformation", Oxford: Pergamon-Elsevier Science, 1998.

4. The KTH Entrepreneurial Faculty Project, VINNOVA Report VR 2005:13, ISBN 91-85084-44-1, 2005.

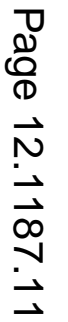

